\title{
LA GUERRA BIOLÓGICA Y QUÍMICA EN LA GRECIA ANTIGUA (SIGLOS VIII - IV A. C.)
}

\section{The biological and chemical warfare in Ancient Greece ( $8^{\text {th }}-4^{\text {th }}$ centuries bc)}

\author{
Susana Blanco Rodríguez \\ UVIGO. La Estela de Numancia
}

Recibido: $14 / 03 / 20$

Aceptado: 22/07/20

\section{Resumen}

Cuando escuchamos la expresión "guerra biológica o bacteriológica" pensamos en un tipo de ofensiva en la que se utilizan armas que contienen virus o bacterias capaces de infligir un dańo masivo sobre el ejército o la población civil y que su invención es algo más o menos reciente. Sin embargo, los griegos de la antigüedad ya conocían los efectos que determinados venenos y sustancias, ya fuesen de origen vegetal o animal, producían en el cuerpo humano. Utilizarlos en el terreno militar fue cuestión de tiempo. En contra de lo que se podría pensar, construir armas químicas y biológicas no era algo complicado ni exigía grandes conocimientos: la mayoría de estas armas tenían una tecnología sencilla, lo que no le restaba eficacia.

Las fuentes griegas apenas mencionan este tipo de armas que no sólo fueron utilizadas por los humanos; en la esfera mítica también encontramos ejemplos de su empleo. Este recelo podría deberse a que se consideraban armas crueles y deshonrosas, que simbolizaban la guerra despiadada, astuta, secreta y al margen de todo precepto moral; además solían provocar heridas dolorosas e incurables y, en el peor de los casos, una muerte angustiosa.
\end{abstract}

\section{Abstract}

When we hear the expression "biological or bacteriological warfare" we think of a type of offensive with weapons containing viruses or bacteria and capable of inflicting massive damage on the army or civilian population. We also might believe that their invention is more or less recent. However, the ancient Greeks already knew the effects produced by certain venoms and substances in the human body, whether those substances were of plant or animal origin. Using them in the military field was a matter of time. Contrary to what is commonly believed, building chemical and biological weapons was not complicated, and it did not require great technical and scientific knowledge. Thus, most of these weapons had simple technology, which did not detract from their effectiveness.

Greek sources hardly mention this type of weapon, that was used not only by humans, but there are also various examples of their use in the mythological sphere. This lack of references could be because they were considered cruel and dishonorable weapons, symbolizing merciless, cunning, secret and immoral warfare. Besides, they often caused painful and incurable wounds and, in the worst case, an agonizing death. 
En definitiva, este tipo de armas contradecían el ideal griego de guerra justa, respetuosa y sujeta a unos principios éticos aprobados por la sociedad. Sin embargo, en la Grecia Antigua, el principio de orden y justicia de la guerra, era frágil y recurrir a tretas inteligentes que sorprendieran al enemigo, en el fondo, estaba bien visto. Por lo tanto, establecer dónde estaba el límite entre lo aceptable y lo reprobable era difícil de precisar y es justamente en este contexto donde se encuadrarían las armas biológicas, cuyo uso en Grecia se remontaría a fechas tempranas y a los relatos míticos.

\section{Palabras clave}

Guerra biológica, guerra tóxica, armas químicas, sustancias nocivas, Heracles, Odiseo, veneno, fuego, flechas, scythicon.
In short, this type of weapon contradicted the Greek ideal of a fair and respectful war, subject to a series of ethical principles approved by the Greek society. However, the principle of order and fairness in warfare was fragile in Ancient Greece. Thus, resorting to clever tricks to surprise the enemy was, at heart, well regarded and, to some extent, admirable. It was, therefore, difficult to establish where the boundaries between the acceptable and the reprehensible laid. It is precisely in this context that biological weapons would be placed. The use of these weapons in Greece would date back to early times and mythical tales.

\section{Keywords}

Biological warfare, toxic warfare, chemical weapons, venom, Heracles, Odysseus, poison, fire, arrows, scythicon. 


\section{La utilización de toxinas en la mitología}

Las primeras menciones sobre el empleo de sustancias nocivas en la guerra las encontramos en las narraciones míticas. Al igual que ocurría en la realidad, las divinidades que abatían al enemigo con armas tóxicas no eran respetadas. Las flechas del dios Apolo podían provocar enfermedades en forma de plaga, aunque también tenían poderes sanadores. La Ilíada comienza con el dios tensando su arco contra los aqueos $y$, aunque en un principio, sus objetivos eran los perros y mulos, finalmente sus flechas acabaron afectando al grueso del ejército (Hom. Il. I, 50 - 70 y 376 - 386 $)^{1}$. Apolo no fue la única divinidad que provocó plagas; Ovidio relata que Hera envió una terrible enfermedad que diezmó la población de Egina (Metamorfosis, VII, 530 y ss.). El propio Aquiles es consciente de que, ante una epidemia, los soldados no pueden hacer nada, salvo abandonar la contienda.

También el mítico Heracles recurrió al empleo de proyectiles manipulados para matar a Hidra de Lerma, un monstruo de tamaño descomunal y numerosas cabezas de las cuales una, era inmortal. En esta ocasión el héroe se valió de flechas impregnadas en resina de pino a las que prendió fuego para forzar la salida del monstruo de su madriguera. Cuando lo logró comenzó a eliminar las cabezas de Hidra. No le resultó fácil hacerlo ya que cada vez que machacaba una de las cabezas, brotaban dos en su lugar. Para aniquilar al monstruo, el héroe le pidió a Yolao que incendiara un bosque cercano y con los tizones, cauterizó las cabezas de modo que dejaron de regenerarse. Finalmente seccionó la cabeza inmortal del monstruo y la enterró (Ov. 9. 62, 7 - 5; Apolodoro, Biblioteca mitológica, 2. 5. 2; Diodoro Sículo, Biblioteca bistórica, IV, 11 - 5). Antes de sellar la tumba con una enorme piedra "sumergió en su bilis las puntas de sus dardos, a fin de que cada dardo lanzado provocara, debido a su punta una herida incurable" (Diod. Biblioteca, IV, 11 - 5). De este modo el héroe ideó una de las primeras armas químicas que se utilizaron en Grecia.

Si Heracles fue el primero en manipular sus flechas con veneno de serpiente, Odiseo fue el primer personaje legendario que utilizó toxinas vegetales con la misma finalidad. El héroe acudió a Efira en busca de veneno para emponzoñar sus flechas. Aunque inicialmente, el rey Ilo le negó el veneno presuponiendo que lo iba a utilizar con fines bélicos y no cinegéticos (ámbito en el que sí se consideraba lícito utilizar flechas envenenadas), Odiseo terminó haciéndose con él. Aunque las fuentes no revelan cual fue el veneno que obtuvo el héroe, sabemos que en Efira abundaba el acónito, el eléboro negro o la belladona, plantas que supuestamente se nutrían de los vapores nocivos del hades y que resultaban altamente tóxicas. Tiempo después, uno de los pretendientes de Penélope especula con la posibilidad

1 Las abreviaturas utilizadas para las fuentes clásicas son las recogidas en el DGE-CSIC. 
de que Telémaco, hijo de Odiseo, viajase también a Éfira para hacerse con alguna planta para envenenar el vino que consumían y terminar así con ellos (Hom. Odisea. II, 328).

Aunque las armas envenenadas estaban mal vistas, en algunos momentos se aceptaba su uso e incluso Atenea, firme defensora y representante de la guerra legítima y justa, aprobó que Telémaco, recurriera a ellas. No obstante, hay que matizar que la diosa justifica esta actuación tras comprobar los agravios que los pretendientes infringían a la familia y hacienda de Odiseo (Hom. Od. I, 260).

Resulta muy llamativo que, en el universo mítico, todos o casi todos los que manipularon sus armas con veneno terminaron siendo heridos o destruidos por agentes tóxicos, ya fuese de forma accidental o como castigo a sus actos. Por ejemplo, Odiseo, quien se hizo con las armas de Aquiles al morir éste, sucumbió a manos de su hijo Telégono (Sófocles, Ayax, 1336 y Filotectes 55 - 64 y 360 y ss; Quinto de Esmirna, Posthoméricas, V, 1 y ss.). El joven al saber que su padre era Odiseo fue a buscarlo. Llegó a Ítaca y se apoderó de parte de sus rebaños y cuando Odiseo acudió a recuperarlos, Telégono lo mató con una lanza en la que Hefesto había colocado un aguijón de raya (Apolodoro, Epitomes, VII, 36 y ss.). Tampoco Heracles se libró del sufrimiento y de una muerte cruenta. El héroe pensó que podía controlar las flechas envenenadas, pero en realidad estas sólo sirvieron para herir o matar a sus propios amigos y a él mismo. No obstante, es necesario matizar que Heracles no fue herido por un arma, sino que fue víctima de un envenenamiento: Heracles hirió al centauro Neso con una flecha emponzoñada cuando este trató de violar a Deyanira. Antes de morir, el centauro engañó a la joven haciéndole creer que si mezclaba su semen con la sangre que manaba de su herida obtendría un filtro amoroso para Heracles. Posteriormente Yole, temerosa de que Heracles amara más a Deyanira que a ella, impregnó con la poción el manto del héroe. Durante la celebración de un sacrificio, el manto se calentó y el veneno de la Hidra empezó a hacer su efecto, corrompiendo dolorosamente la piel del héroe (Apollod. Biblioteca, II, 7 - 6 y ss; Ov. IX, 140 y ss.). Heracles no soportó el sufrimiento y puso fin a su vida quemándose en una hoguera.

Antes de que todo esto sucediera el héroe mató a Quirón y Folo. Mientras trataba de dar caza al jabalí de Erimanto, Heracles fue a visitar al centauro Folo, quien lo recibió hospitalariamente. El héroe le pidió vino y Folo le advirtió que sólo le quedaba una jarra que pertenecía a todos los centauros. Al destapar la jarra, los centauros se presentaron armados y Heracles repelió la agresión arrojándoles una lluvia de flechas envenenadas. Los centauros se refugiaron en la cueva de Quirón (amigo del héroe) quién resultó herido por una de las flechas. La herida le provocó un dolor tan insoportable que el centauro renunció a su inmortalidad para poner fin a su sufrimiento. Folo por su parte, extrajo una flecha del cuerpo de un centau- 
ro muerto para examinarla, pero esta se le escurrió de las manos y terminó clavada en una de sus patas. Como le ocurrió a Quirón, su muerte fue agónica (Apollod. Biblioteca, II, 5 - 4 y Epít. III, 17 - 20). Aunque circunscritos a la esfera mítica, estos episodios demuestran la peligrosidad que implicaba la utilización de armas envenenadas no sólo porque un simple roce con ellas podría provocar consecuencias trágicas; también porque durante un enfrentamiento, los héroes perdieron el control sobre ellas, hiriendo tanto a enemigos como a camaradas. Como veremos, ambas situaciones son extrapolables a la realidad de un campo de batalla.

Las trágicas consecuencias desatadas con la invención de las flechas envenenadas no terminaron con la muerte de Heracles. Su arco y sus flechas "portadoras de muerte" pasaron a manos de Filotectes quien participó en la Guerra de Troya (S. Ph. 105). Homero menciona que comandó 7 de las 1200 naves que partieron hacia Troya y que cada una de estas naves contaba a bordo con 50 remeros "buenos conocedores también del arco en los duros combates” (Il. II, 720). El poeta no afirma explícitamente si Filotectes equipó a estos arqueros y a él mismo con flechas envenenadas; sin embargo, el relato de Sófocles confirma que Filotectes portaba estas flechas durante la travesía (S. Ph. 1 y ss.). En cualquier caso, durante el viaje el héroe se lesionó en un pie. La sintomatología de su herida, necrosada, supurante, que no cicatrizaba y que además desprendía un olor nauseabundo concuerda con una lesión producida por un arma envenenada o por la mordedura de serpiente (S. Ph. 268 y 1325; Hom. Il. II, 720). El héroe fue abandonado en la Isla de Crisa, donde su herida fue empeorando progresivamente. Transcurridos diez años, un grupo de hombres dirigidos por Odiseo fue en su busca para hacerse con sus flechas ${ }^{2}$. Aunque Filotectes se negó a entregárselas, el astuto Odiseo, acabó haciéndose con ellas, una actuación que motivó las críticas de Neptoleno (Q. S. IX, 355 y ss; S. Ph. 87 y ss; 840; 1225 - 1245).

Aunque que el empleo de armas envenenadas suscitaba como ya señalamos cierto recelo, los aqueos, entre los que se encontraría Filotectes, no dudaron en atacar con ellas a los troyanos, pero también ellos resultaron heridos con ellas:

- Menelao resultó herido por una flecha que le provocó una herida de la que brotaba sangre negra.

- Eurípilo fue herido por una flecha que le provocó sudores y un sangrado negro.

- Aquiles murió abatido por una flecha a las puertas de Troya. Héctor, antes de morir vaticinó a Aquiles que Paris y Febo Apolo serían los responsables de su muerte (Hom. Il. XX, 350 y XXI, 270). Otras fuentes señalan que fue Apolo

2 Este episodio forma parte de la guerra de Troya: un oráculo predijo que los aqueos lograrían someter a los troyanos si utilizaban las flechas de Heracles. 
quien disparó la mortal flecha (Q. S. III, 60; S. Ph. 335). Siguiendo a Quinto de Esmirna, el héroe sumido en profundos dolores criticó esta actuación ya que morir atacado por la espalda y por una flecha envenenada suponía un deshonor. Por ello instó a su adversario (en realidad sospechaba que se trataba de una divinidad) a que diera la cara y pelear frente a frente para morir así, con honor. La escena no sólo pone de manifiesto la impotencia del héroe y su frustración por tener que morir deshonrosamente, sino que nuevamente se pone de manifiesto que ante las armas manipuladas y, por tanto, más letales, de nada servían el coraje, la fortaleza física, la destreza militar o la resistencia de los guerreros.

- Filotectes hirió a Paris con una flecha que le provocó un gran sufrimiento hasta que finalmente, murió (S. Ph. 1425; Q. S. X, 235 y ss; X, 270).

Otra táctica bélica que hunde sus raíces en la mitología es la que consistía en adulterar la comida y la bebida del enemigo. Muchos mitos griegos relatan cómo diversas criaturas semihumanas (tritones, centauros, sátiros, etc.), fueron abatidas o capturadas atrayéndolas con vino adulterado. Sin duda, la experta en este tipo de artimañas fue Medea, quien aprendió los principios de la hechicería de la mano de su tía, Circe. Entre las actuaciones más importantes de Medea estarían el envenenamiento del dragón que protegía el vellocino de oro y la preparación de pócimas para proteger a Jasón y a los argonautas de sus perseguidores.

En la mitología también es posible encontrar episodios en los que se intentó propagar una enfermedad o plaga de forma premeditada, estrategia que con el paso del tiempo se trasladó al campo de batalla: así Apolo además de disparar dardos infecciosos, provocaba plagas de roedores y Pandora abrió por error la caja que contenía todos los males del mundo. El mito de Pandora resulta especialmente significativo ya que constituye el primer ejemplo de confinar una plaga o enfermedad en un recipiente, algo que a priori, podría parecer una invención reciente de la guerra química.

\section{Del mito a la realidad}

Teóricamente los griegos preferían el enfrentamiento frontal, cuerpo a cuerpo, al empleo de ardides y la falta de principios y casi siempre trataban de firmar algún acuerdo, más o menos justo, que marcara las pautas del combate. Por ejemplo, podía estipularse el uso o la prohibición de determinadas armas. Esto fue lo que sucedió durante la guerra Lelantina (ca. 700 a. C.), en la que se prohibió el empleo de arcos, hondas y jabalinas. A pesar de esto, la realidad demuestra que los griegos no sólo manipularon las armas y emplearon ardides que sorprendieran al enemigo, 
sino que, si recurriendo a alguna de estas tácticas, se conseguían los objetivos fijados, se justificaba y se elogiaba su utilización.

\subsection{El empleo de flechas envenenadas}

Como en la mitología, una de las primeras armas que se manipularon con toxinas fueron las flechas. A pesar de la importancia que el arco ostentó en Grecia como objeto de prestigio, en el contexto bélico se consideraba un arma de cobardes debido a que los arqueros disparaban desde la distancia, evitando el enfrentamiento cuerpo a cuerpo. Si además manipulaban sus flechas con veneno, su actuación se consideraba todavía más reprobable y cobarde. Claudio Eliano (siglo III d. C.), dedujo que los héroes griegos discurrieron la idea de envenenar sus flechas al contemplar a las avispas "cargar" su aguijón sobre el cadáver de una serpiente, acción muy similar a lo que hizo Heracles con la Hidra de Lerma (Aelian. V, 16). Pedacio Dioscórides (siglo I d. C.), fue el primero en señalar la relación entre las palabras tóxico ("toxicón" = veneno) y flecha ("toxon"), aunque lo hizo matizando que solamente los bárbaros recurrían a la utilización de proyectiles envenenados (Acerca de la materia medicinal y de los venenos mortíferos, VI, 20). Sin embargo, nos consta que los griegos también los utilizaron y que lo hicieron desde fechas tempranas.

La naturaleza proporcionaba una gran variedad de alternativas a la hora de fabricar flechas envenenadas. Generalmente el envenenamiento de las armas, fuesen del tipo que fuesen, estaba asociado a una muerte lenta y dolorosa, algo que, de nuevo, contradecía el ideal de combate justo y honorable. Entre las plantas venenosas más utilizadas en el mundo antiguo destacan:

- El eléboro podía matar un caballo o un buey en pocas horas. Su recolección y posterior manipulación resultaba especialmente peligrosa ya que el mínimo roce con la planta podría provocar la muerte.

- El acónito provocaba entre otros efectos dolor abdominal, vómitos, sed intensa, debilidad y parálisis neuromuscular.

- El tejo podía provocar la muerte o un accidente cardiovascular con solo tocarlo.

- La belladona aplicada sobre un arma, prolongaba sus efectos mortíferos durante años; por ejemplo, una hoja de espada impregnada con ella mantenía la toxicidad durante 30 años; causaba mareos, agitación delirante, coma y finalmente la muerte.

- El rododendro producía la muerte por parada cardiorespiratoria.

- El beleño debía recolectarse sin tocarlo (Aelian. IX, 32). El envenenamiento con esta planta provocaba convulsiones violentas, psicosis y la muerte.

- La cicuta congelaba y enfriaba la sangre (Aelian. IV, 23). 
Aunque se solían utilizar mayoritariamente en los rituales religiosos y funerarios y en medicina, no podemos descartar que en determinados momentos los griegos también utilizasen con fines bélicos la adormidera y el opio. Nos consta que hacia el siglo XV a. C., Tebas contaba con plantaciones de opio y Hesíodo (siglo VII a. C.), señala que en Mekone, próxima a Corinto, abundaban las adormideras, planta que ya se utilizaba al menos desde la Edad del Bronce ${ }^{3}$. Para untar las flechas también se utilizaron venenos como el helenion y el ninon, pero a día de hoy no se han identificado.

Algunos animales también proporcionaban directa o indirectamente, venenos altamente letales. Claudio Eliano, menciona la elevada toxicidad de los excrementos del dikairon, una especie de escarabajo pelotero (Aelian. IV, 41). El mismo autor menciona que no existía ningún remedio para curar la herida producida por la espina o el aguijón, dependiendo de la especie, de un pez raya (trygon) ya que la muerte sobrevenía instantáneamente (Aelian. I, 56; II, 36 y 50; VIII, 26). Además, en el caso de clavarse el aguijón, al ser este rígido y dentado provocaba heridas muy profundas e irregulares y su extracción era dificultosa. El veneno del pez raya se caracterizaba por tener espasmos musculares, parálisis, dolor e irritación y fuertes infecciones. Si la herida se infringía en el pecho provocaba un paro cardíaco. También las medusas y los erizos de mar resultaban peligrosos. La picadura de medusa podía producir una ralentización del sistema nervioso central y desencadenar un paro cardíaco. Algo similar ocurría con las púas de los erizos, cuyo efecto podía agravarse si se clavaban cerca de un hueso, un tendón o un nervio.

Pero sin duda, el veneno más utilizado en la Grecia Antigua fue el proporcionado por las serpientes, animal al que los griegos temían especialmente. Homero traslada este temor al ámbito bélico, concretamente al momento en que Paris rehúsa enfrentarse en el cuerpo a cuerpo con Menelao:

"E igual que cuando uno, al ver una serpiente en la cañada de una montaña, recula apartándose, y bajo su piel el temblor embarga sus miembros, y se vuelve atrás y la palidez se apodera de sus mejillas, así se sumergió de nuevo entre la multitud de los altaneros troyanos Alejandro, semejante a los dioses, presa de miedo ante el hijo de Atreo".

(Hom. Il. III, 30 y ss.)

Existía una gran variedad de serpientes venosas, tanto terrestres como marítimas, aunque la más conocida y temida era la víbora (Aelian. IV, 36 y 57; VI, 38;

3 Para más información sobre el uso de la amapola / adormidera en el mundo griego consúltese el artículo de CAROD - ARTAL. F. J: "Plantas psicoactivas en la Antigua Grecia", en Neurosciences and History 1 (1). Ed. Sociedad española de Neurología, 2013, pp. 31 y ss. 
$\mathrm{XV}, 13$; XVII, 4). Las heridas provocadas por una flecha impregnada con veneno de serpiente se caracterizaban por una necrosis entorno a la herida, brotes de sangre azul o negra que podían prolongarse en el tiempo, proliferación de yagas pútridas y hemorragias, inflamación de las extremidades, aparición de vómitos, "dolor helado” en torno al corazón, convulsiones y pérdida de conocimiento. Tras una dura agonía, se producía la muerte.

Virgilio afirmaba que Ámico, el compañero de Eneas era el más hábil a la hora manipular las flechas y armar el hierro de ponzoña (Eneida, IX, 771 - 773). Sin embargo, los escitas quienes emponzoñaban sus flechas con una mezcla denominada scythicon ("toxina escita") no se quedaban atrás. Aunque algunos escritores antiguos afirmaban que utilizaban cicuta para emponzoñar sus dardos, actualmente se acepta que el principal ingrediente del scythicon sería el veneno de víbora ${ }^{4}$. Los escitas mataban a las víboras justo después de parir, cuando se encontraban debilitadas y las dejaban al sol para que se descompusieran. A continuación, mezclaban los restos del réptil con estiércol y un suero hecho a partir de sangre humana (Aelian. IX, 15) $)^{5}$. El scytbicon desprendía un hedor desagradable, penetrante y fácilmente identificable durante el enfrentamiento. Esto afectaría psicológicamente a los soldados pues eran plenamente conscientes de que se estaban utilizando flechas envenenadas. También la decoración de los astiles de las flechas y la forma de las puntas (a modo de arpones, espinas o garfios), pudieron contribuir a intimidar al adversario ${ }^{6}$. Plinio parece sugerir que también los oreítas impregnaban sus flechas con el veneno de serpiente (Historia Natural, XV, 7).

El desarrollo y producción de armas envenenadas, estaría asociado a la búsqueda de antídotos y tratamientos para contrarrestar sus efectos. Las fuentes aluden a algunos remedios que se utilizaron en la Grecia Antigua. Claudio Eliano afirma que con ungüentos, pócimas o ensalmos se podían remediar las picaduras de serpiente (que en principio eran incurables), salvo la del áspid o cobra egipcia (Aelian. I, 54; VI, 38; XII, 32); si esta, antes de morder a su víctima había comido una rana su picadura resultaba insufrible (Aelian. IX, 15). Sófocles narra que Filotectes adormecía su herida (supuestamente provocada por una serpiente) hasta

4 Cf. MAYOR, A: Fuego griego, flechas envenenadas y escorpiones: La guerra química y biológica en la antigüedad. Ed. Desperta Ferro, Madrid, 2018, p. 34.

5 Un procedimiento similar, pero sin el suero se realizaba en la India con la serpiente púrpura (Aelian. IV, 36).

6 Generalmente los escitas decoraban los astiles de sus flechas con motivos zigzagueantes y ondulados que podrían estar inspirados en la piel de las serpientes. Los soldados al ver estas flechas sabrían que el enemigo disponía de arqueros escitas entre sus filas. No obstante, la decoración también podría ser algo personal y tener una finalidad práctica al permitir al arquero diferenciar que flechas eran para cazar y cuales se destinaban a la guerra. También habría flechas sin decoración; la opinión más difundida es que este tipo de flechas no estarían envenenadas y que probablemente se emplearían para entrenar. 
calmarla por completo con una planta de la que no especifica su nombre (Ph. 649); según Flavio Arriano durante su incursión en la India, Alejandro recurrió médicos indios conocedores de plantas que curaban las picaduras de serpiente y otras enfermedades (Anábasis de Alejandro, VIII, 11).

Otro remedio, no exento de peligro, consistía en que un médico o un compañero succionara directamente el veneno de la herida (Hom. Il. IV, 148 - 219); también se podían aplicar sanguijuelas (muy utilizadas por los troyanos) sobre las heridas o se extraer la ponzoña con diversos utensilios. Un método más sofisticado y menos utilizado consistía en inmunizar a los soldados contra el veneno; consistía en hacerles ingerir pequeñas cantidades de veneno acompañados de sus respectivos antídotos. Un caso excepcional era el de los psilos libios que no sentían las mordeduras de las serpientes, las arañas y los escorpiones (Aelian. XVI, 27). Plinio aseguraba que las serpientes huían de ellos porque su cuerpo generaba una sustancia mortífera para ellas y que, simplemente su olor, las adormecía (H. N. VII, 14; VIII, 93).

Aunque los médicos acompañaban al ejército (Hom. Il. XI, 514), en las descripciones homéricas es perceptible que los soldados también conocían determinadas técnicas para curar o al menos aliviar las heridas de guerra (extracción de flechas, contener hemorragias, aplicar cataplasmas o determinadas substancias sobre las heridas, hacer vendajes, etc.): Aquiles, quien es el más eficaz matando, también resulta ser el más experto en el arte de curar, le vendó el brazo a su amigo Patroclo cuando una flecha lo alcanzó, escena plasmada con bastante realismo en un kilix de figuras rojas (ca. 500 a. C.); Agenor vendó con lana de oveja la mano de Heleno (Il. XIII, 595); Patroclo curó a Eurípilo extrayéndole una flecha y colocándole encima de la herida una raíz amarga que desmenuzó con las manos (Il. XI, 809 - 840), etc. Otras heridas, como la sufrida por Télefo cuando se clavó la lanza de Aquiles que recordemos iba provista de un aguijón de raya, se curaron gracias a la aplicación de óxido de hierro sobre ella (Apollod. Epit. III, 3. 20). Claudio Eliano también alude a los conocimientos médicos de los héroes e hijos de los dioses (Aelian. II, 18). A pesar de todo, el índice de supervivencia a una herida de guerra era reducido: en Homero se contabilizan un total de 147 heridas lo que sitúa la tasa de supervivencia en torno al 77,6\% $\%^{7}$.

Entre el mito y la realidad se encuadraría la curación de Ptolomeo herido seguramente por una flecha oreíta emponzoñada con veneno de serpiente. Según Plinio, Alejandro Magno tuvo un sueño en el que supuestamente le revelaron la existencia de una raíz que, triturada, curaría la herida. Posteriormente el autor se contradice afirmando que los más lógico es que alguien que conocía el remedio se lo revelara $(H . N$. XV, 7). En cualquier caso, el antídoto funcionó y sirvió para que

7 Cf. MAYOR, A: Fuego griego...Op. Cit. P. 66. 
los bárbaros se rindieran ante el rey macedonio. No fue este el único ejemplo de curación mítica: Peón curó una herida de Hades esparciendo sobre ella ungüentos y otra de Ares aplicándole drogas calmantes (Hom. Il. V, 400 y 900).

\subsection{El envenenamiento masivo de una población o del enemigo}

El ataque deliberado contra una población civil estaba prohibido por las leyes de la guerra justa. No obstante, anteponiendo lo que se presuponía lícito a lo que realmente ocurría, en determinados momentos (por ejemplo, durante los asedios) se consideraba enemigos a todos los habitantes de la ciudad y por tanto existían distintas estrategias para forzar su rendición o, en el peor de los casos, su aniquilación. Entre estas estrategias se incluían el envenenamiento del suministro de las bebidas o de los alimentos. El primer caso documentado de una población civil envenenada masivamente con fines bélicos se produjo en la ciudad de Cirra durante la Primera Guerra Sagrada (590 a. C.). La liga Anfictiónica, creada para defender el Santuario de Delfos decidió envenenar el agua de la ciudad. Existen distintas versiones sobre este episodio: Frontino narra que fue Clistenes de Sición quien cortó las tuberías de agua, las envenenó con eléboro y posteriormente restableció el suministro; en la versión de Tésalo, aprovechando que un caballo rompió el conducto del agua, Nebros sugirió que se vertiera en él algún tipo veneno cuyo nombre no especifica ${ }^{8}$; según Polieno fue Euríloco quien sugirió hacer acopio de una gran cantidad de eléboro de la zona de Anticira (puerto de Cirra) y envenenar con ella el agua de la ciudad (Estratagemas, VI, 13); Pausanias narra que Solón propuso desviar el río Pleistos para dejar desabastecida la ciudad y que, tras contaminar el río con eléboro, restableció el suministro de agua (Descripción de Grecia, X, 37. 7). Finalmente, Estrabón menciona la abundancia de eléboro en las cercanías de Cirra pero omite si la planta estuvo o no relacionada con su destrucción (Geografía, IX, 3. 3). Es posible que la existencia de cuatro versiones diferentes esté relacionada con la controversia que el empleo de armas biológicas suscitaba en la Antigüiedad Griega o más probablemente con los crueles efectos que el veneno produjo en la población. En cualquier caso, esta actuación removió las conciencias y tras la rendición de Cirra, la Anfictionía de Delfos, por unanimidad, decidió que el envenenamiento de las aguas era una práctica cruel e inaceptable a la que no se debería recurrir en el futuro.

Como solía suceder, la medida fue una utopía y, en sucesivos conflictos, ya fuese como táctica de ataque o de defensa, la norma se incumplió:

- En el año 478 a. C., los atenienses trataban de frenar infructuosamente al ejército de Jerjes. Cuando la situación ya parecía insalvable, los atenienses

8 Cf. MAYOR, A: Fuego griego...Op. Cit. Pp. 69 - 70.

Minius, n. ${ }^{\circ} 25,2020$ ( 9-31) / ISSN: 1131-5989 
decidieron abandonar la ciudad, no sin antes envenenar el agua. En este caso el envenenamiento fue aceptado por los habitantes de la ciudad y por los griegos en general ya que formaba parte de una práctica defensiva antigua y tolerada denominada "tierra quemada". Esta táctica consistía en arruinar las cosechas y las provisiones de agua para que el enemigo no pudiera sacarles provecho.

- Durante la guerra del Peloponeso (431 - 404 a. C.), los atenienses destruyeron las tuberías de agua de Siracusa (415 - 413 a. C.). En esta ocasión se puso de manifiesto que la guerra biológica podía convertirse en un arma de doble filo: los siracusanos no se amedrentaron y contraatacaron utilizando la misma estrategia y privaron a los atenienses de agua. Finalmente, tras una incesante persecución tierra adentro, los atenienses, exasperados y muchos de ellos enfermos, llegaron a un río. La debilidad y el desconcierto fue aprovechado por los siracusanos para masacrar a los griegos desde los acantilados (Th. 7. 84).

- Un siglo después de que esto sucediera, Eneas el Táctico escribió su famoso Tratado de poliorcética en el que defendía el envenenamiento de agua como táctica bélica.

Los soldados eran especialmente vulnerables a cualquier trampa relacionada con la comida y la bebida, especialmente el vino (utilizado tanto en la vida cotidiana como en los sacrificios) por lo que se recurrió a sustancias hipnóticas o alucinógenas para envenenarlas. Como ocurría con la táctica anterior, era algo que se consideraba poco ético y propio de los "bárbaros". A pesar de que los griegos recordaban lo ocurrido en Troya cuando los aqueos dejaron a las puertas de Ilión el famoso caballo de madera, que resultó ser una trampa mortal, los soldados continuaron aceptando regalos del enemigo sin pararse a pensar que la historia podía volver a repetirse. Polieno recoge un episodio que pudo ocurrir en torno al año 1000 a. C., durante la colonización griega de Jonia. Cnopo, rey de Atenas, trataba de apoderarse infructuosamente de la colonia de Eritras. Un oráculo le aconsejó llamar a Crisame, sacerdotisa de la diosa Hécate en Tesalia y experta en hierbas venenosas y pócimas mortíferas. Crisame ideó un macabro plan para rendir la ciudad: seleccionó el mejor toro del rebaño de Cnopo, lo revistió con un manto púrpura, sobredoró sus cuernos y lo adornó con cintas. A continuación, le dio de comer al animal hierbas enloquecedoras y levantó un altar a la vista del enemigo. Cuando el toro era conducido al altar, las hierbas comenzaron a hacer su efecto y éste, enloquecido, terminó en el campamento del enemigo. Los jonios lo consideraron signo de buen presagio y sacrificaron al animal. Tan pronto comieron su carne, las drogas hicieron su efecto y los jonios empezaron a saltar, a correr en todas las direcciones y abandonaron sus puestos de guardia. Los atenienses aprovecharon del desorden para masacrarlos y hacerse con la ciudad (Polyaen, VIII, 43). Descono- 
cemos el tipo de droga que utilizó la sacerdotisa, pero por los efectos que provocó podría tratarse de estricnina, destilada a partir de la belladona.

Otro caso vinculado a la ingesta de comida emponzoñada los encontramos en Polieno y Heródoto. El primero narra como en el año 530 a. C., los masagetas fingieron huir de Ciro el Grande; como parte del engaño, dejaron en el campamento vino y comida en abundancia $y$, aunque no se menciona abiertamente, es posible que la reina Tomiris ordenara adulterar los alimentos con algún tipo de droga. Esto explicaría que los soldados se quedaran profundamente dormidos y apenas ofrecieran resistencia (Polyaen. VIII, 28). Heródoto ofrece otra versión de los hechos totalmente diferente: Ciro embaucó a los masagetas proporcionándoles vino de alta graduación. Los guerreros masagetas estaban habituados a consumir estupefacientes como el hachís y leche de yegua fermentada, pero desconocían los efectos del vino y no tardaron en embriagarse (Historia, I, 201 y ss.). El persa aprovechó la situación para terminar con los masagetas. Esta actuación fue reprobada por la reina Tomiris quien le lanzó una amenaza de muerte que finalmente cumpliría (Hdt. I, 214).

Ignoramos qué versión de los acontecimientos es la más fidedigna, pero en cualquiera de ellas se evidencia que, aunque no era lo más frecuente, en la Grecia Antigua sabían sacar partido a los descuidos del enemigo con la comida y la bebida y que esta práctica se consideraba deshonesta y odiosa, pero no injusta pues se suponía que un general debía de ser capaz de refrenar el comportamiento de sus hombres y que estos siempre podían elegir entre entregarse o rechazar los placeres que les ofrecían.

\subsection{Patógenos utilizados como armas}

Los griegos de la antigüedad sabían que las personas o los animales aquejados por agentes infecciosos (hongos, virus, parásitos, bacterias, etc.) podían transmitir enfermedades; tal vez lo dedujeran a partir de sucesos como los ocurridos durante la guerra de Troya donde la peste minó considerablemente al ejército aqueo (Hom. Il. I, 50 - 70 y 376 - 386) ${ }^{9}$, o tal vez lo aprendieran enfrentándose a la realidad. En el año 430 a. C., mientras los atenienses estaban siendo asediados por los espartanos, por el puerto de Atenas se extendió una epidemia. Para algunos historiadores griegos, la enfermedad tendría su origen en el envenenamiento del agua por parte de los espartanos. En cambio, Tucídides señala que la peste fue importada de Egipto, y que, difundiéndose por Persia y Libia, llegó a Atenas. Según su versión el contacto con los enfermos, facilitó la propagación de la epidemia, que terminó afectando también a los médicos que los atendían (Th. 2. 47 y 3. 87). Diodoro Sículo, en cam-

9 Según la RAE el término "peste" puede aludir a cualquier enfermedad que cause gran mortandad y este es el sentido con el que se utilizó la palabra en la Antigua Grecia. 
bio, ofrece una descripción menos dramática de los acontecimientos. Los atenienses (entre los que se incluían gentes de distinta procedencia que habían llegado a la ciudad) decidieron no presentar batalla a los lacedemonios y se protegieron en el interior de los muros: el hacinamiento y el aire viciado facilitaron la propagación de la enfermedad (Diod. XII, 45. 2) ${ }^{10}$. Más cruenta resulta la descripción que hace Ovidio de la peste que sufrió Egina. Los enfermos se pegaron a las fuentes, ríos y pozos para beber; al no poder levantarse, muchos murieron en ellos. Aun sabiendo que el agua estaba corrompida por los cadáveres, la gente sana la bebió. El poeta coincide con Tucídides al señalar que los que tenían contacto con los enfermos se contagiaban fácilmente (Ov. VII, 530). También Agrigento (406 a. C.) y Siracusa (396 a. C.) sufrieron episodios de peste.

Emplear agentes infecciosos con fines militares fue relativamente sencillo. La táctica más simple consistía en obligar al enemigo a acampar en lugares insalubres y forzarlos a comer y beber sustancias tóxicas o nauseabundas, con la intención de que estos enfermasen. Por ejemplo, durante la invasión de Sicilia (415 - 413 a. C.), muchos soldados atenienses sufrieron fiebres palúdicas (probablemente malaria o disentería) contraídas en las ciénagas donde acamparon durante el verano. Desconocemos si los atenienses acamparon en este lugar por un descuido o si lo hicieron obligados por los sicilianos. A pesar de la insistencia de Jenofonte para que los generales velasen por la salud de los soldados y establecieran campamentos siempre en lugares salubres, lejos de humedales, ciénagas, terrenos fangosos o con abundante vegetación, etc., especialmente propicios para la proliferación de mosquitos, moscas y garrapatas que podían transmitir enfermedades, abundan los ejemplos en los que el ejército se vio diezmado por desoír esta recomendación. Por ejemplo, en el año 397 a. C., los cartagineses acamparon en Sicilia, en el mismo lugar donde años atrás lo hicieron los atenienses, con idénticos resultados. Polieno menciona que Clearco ideó un macabro plan para deshacerse de los hombres de Heraclea que se oponían a su gobierno: ordenó la leva de todos los varones entre 15 y 65 años con el pretexto de sitiar Ástaco, ciudad de Tracia que estaba rodeada de ciénagas y pantanos (363 a. C.). Una vez en sus inmediaciones, Clearco y los extranjeros que lo acompañaban acamparon en lugar elevado y salubre mientras que los heracleotas lo hicieron en el cenagal. Por si esta táctica fracasaba, también los obligó a hacer continuas guardias y mantuvo el asedio durante todo el verano, de modo que la insalubridad del ambiente y el cansancio minaron su salud hasta el punto de que todos ellos murieron. El general regresó a Heraclea alegando que una plaga había

10 Para más información sobre la Peste de Atenas y las últimas interpretaciones consúltese el artículo de CARREÑO GUERRA, M. P: "Guerra y peste en Atenas. Revisión sobre el posible origen de la epidemia ateniense (430 - 426 a. C.), en Asclepio, no 71 (1), 2019, p. 249. 
acabado con todos los ciudadanos (Polyaen. II, 30). En este caso, instalar al ejército en un lugar insalubre resulta especialmente espantoso y censurable ya que el general recurriendo a esta estrategia pudo destruir a la totalidad del ejército.

Beber agua en mal estado era otra forma de contraer enfermedades como el cólera, la hepatitis, la diarrea, la fiebre tifoidea, etc. No siempre era el enemigo quien emponzoñaba el agua; ocasionalmente era la imprudencia de los soldados la que corrompía el agua. Por ejemplo, durante su huida, los persas, bebieron atropelladamente agua, lo que provocó que esta se enfangara y que muchos de ellos enfermasen (Q. C. Historia de Alejandro Magno, IV, 16. 13). Algo parecido le sucedió a Alejandro Magno en el 325 a. C., durante la campaña de Gedrosia (Baluchistán, Pakistan); la falta de agua y la dureza de la marcha a través del desierto, entre otras cosas, complicaron la situación de los soldados macedonios y aunque Alejandro estableció los campamentos a cierta distancia de los pozos para evitar que los soldados bebieran en exceso, no pudo evitar que alguno, víctima de la desesperación, se precipitase llevando puesta la armadura al interior de los mismos. Al no poder salir, se ahogaron $y$, al descomponerse, sus cuerpos contaminaron el agua (Str. XV, 2. 6).

Aunque hoy en día sabemos que los patógenos no sobreviven durante mucho tiempo en un cuerpo humano después de fallecer, que es poco probable que las epidemias sean el resultado del contacto con un cadáver y que lo más factible es que los propios supervivientes sean la fuente de un brote de enfermedad, los griegos creían todo lo contrario. En el año 74 a. C., Mitríades, rey del Ponto, asedió Cícico; provocando que su propio ejército pasase hambre y enfermase. Según las fuentes, los cadáveres se apiñaron en las cercanías de la ciudad originándose una epidemia. Algo similar ocurrió en Arbelas (331 a. C.) donde se desató una epidemia provocada por "el hedor de los cadáveres que cubrían la llanura", (Q. C. V, 1.11).

\subsection{El uso de animales como armas}

Desde tiempos remotos, los animales han servido de apoyo logístico a los ejércitos, pero en momentos críticos, se recurrió a ellos como fuerzas de apoyo al combate. En este último caso, los animales podían recibir un entrenamiento previo. Es el caso de los perros que se utilizaban para atacar al enemigo y forzar su huida (Polyaen. VII, 2), un recurso que estaba mal visto y que se consideraba brutal y salvaje. Los hicarnios del Mar Caspio y los magnesios, tribu del nordeste de Grecia eran temidos por los enormes perros con collares de pinchos que acompañaban a los guerreros en el campo de batalla (Aelian. VII, 38). Los perros también resultaban útiles para tareas de vigilancia, como guardianes y como mensajeros en tiempos de paz. Por ejemplo, después de la batalla naval de Naxos (376 a. C.), Nicocles temía una conspiración contra su persona por lo que adoptó distintas medidas para evitarla; 
entre ellas estaba la de realizar rondas con perros en la parte exterior de la muralla (Aen. Tac. Poliorcética, XXII, 20). Excepcionalmente los perros también se utilizaron para evitar las deserciones de los soldados o como escudos humanos (Polyaen. II, 25 y VII, 9). Por su actuación, a alguno de ellos incluso se les reconoció como héroes y fueron honrados como tales; es el caso de Soter, que avisó a los ciudadanos de Corinto del ataque de los nauplios o de un perro que participó en la batalla de Maratón (490 a. C.), que incluso fue representado en las pinturas atenienses que se hicieron tras la victoria (Aelian. VII, 38).

Otros animales utilizados por los griegos en combate fueron los caballos, los camellos y los asnos. Después de la batalla del río Hidaspes (326 a. C.), Alejandro Magno emplearía también elefantes.

Circunstancialmente los animales sirvieron para engañar al enemigo haciéndoles creer que el volumen de los efectivos disponibles para el combate era mayor que el real. En este caso no era necesario un entrenamiento previo de los animales $y$, a pesar que esta estrategia puede parecer chocante, lo cierto es que daba buenos resultados. Alejandro Magno recurrió a ella durante su incursión en Persia: para intimidar a los persas ató ramas de árboles a las colas de las ovejas; estas al moverse, levantaban una nube de polvo que los persas atribuyeron a un gran ejército. Al caer la noche sustituyó las ramas por antorchas, de manera que toda la planicie parecía repleta de fogatas. Idéntica táctica fue utilizada por Tolemeo contra Pérdicas, general de Alejandro Magno en el 321 a. C., durante la campaña en Egipto (Polyaen. VII, 19).

Utilizar animales en el campo de batalla comportaba ciertos riesgos y desventajas. Eneas el Táctico señalaba que si los perros ladraban a destiempo podían resultar perjudiciales y que un animal herido y descontrolado, podía provocar el pánico, no sólo entre sus semejantes sino también entre los soldados que tendrían que luchar y sortear sus embestidas simultáneamente.

Finalmente, los griegos eran conocedores de que ciertas especies animales odiaban instintivamente a otras o se asustaban ante la presencia de bestias que no le resultaban familiares. Era el caso de los caballos y los camellos. Claudio Eliano afirma que cuando Ciro y Creso se enfrentaron en Sardieno (546 a. C.), sabían que ambas especies se detestaban (Aelian, III, 7). Para evitar este rechazo muchos ejércitos, incluido el persa, comenzaron a mezclar camellos y caballos de modo que se familiarizasen y no se asustasen al verse (Aelian. XI, 36). Darío de Persia empleó una táctica similar cuando se enfrentó a los arqueros escitas, pero este caso recurrió los burros, animales totalmente desconocidos en Escitia y cuyos rebuznos espantaron a los caballos.

También los insectos provistos de aguijones resultaban muy efectivos en el campo de batalla. En la Antigüedad existía la creencia de que los animales pro- 
vistos de aguijón acentuaban los efectos de su picadura apropiándose del veneno de serpientes muertas (Aelian. VI, 16 y IX, 15) y que estas a su vez, vigorizaban su ponzoña alimentándose de plantas venenosas. Aunque su aguijón no estuviese emponzoñado, las picaduras de las avispas, avispones y abejas causaban confusión, restaban concentración a los soldados y espantaban a los animales que acompañaban al ejército. Incluso, en un número elevado, podían causar la muerte de un soldado. Plinio estimaba que 27 picaduras de un avispón matarían a un hombre en pocas horas; hoy sabemos que una persona alérgica a estos insectos, puede morir con una sola picadura. En más de una ocasión, la invasión de enjambres provocó el abandono de ciudades enteras. Esto fue lo que sucedió por ejemplo en Fasélide, en Anatolia central y Rauco, en Creta (Aelian. XVII, 35).

La táctica de lanzar colmenas - enjambres de avispas al enemigo ya se utilizaba en el Neolítico. En Grecia, Eneas el Táctico menciona que la liberación de abejas y avispas en los túneles que se excavaban para derribar o rebasar las murallas era una estrategia bélica muy útil. Además de utilizar los insectos lanzándoselos directamente al enemigo, las abejas, en concreto, producían miel, un producto que el enemigo o ellas mismas podían adulterar fácilmente. En el año 401 a. C., terminada la batalla de Cunaxa, Jenofonte regresaba desde Babilonia en dirección al Mar Negro con diez mil mercenarios. El general instaló un campamento en un lugar de la Cólquide donde abundaban las abejas. Los soldados consumieron su miel y sufrieron una extraña reacción: vomitaban, sufrían episodios de diarrea y no podían mantenerse en pie; los que comieron poco parecían borrachos; los que comieron mucho enloquecían e incluso algunos caminaban moribundos. Después de varios días los soldados se recuperaron totalmente (Xen. Anábasis, IV, 8. 20). Lo que ocurrió fue que los soldados sufrieron una intoxicación debido a que las abejas recolectaban el néctar de plantas de rododendro. Los colquidenses lo sabían y por eso utilizaban la miel a modo de tónico o de estupefaciente suave.

\subsection{El empleo del fuego y los productos químicos incendiarios como arma}

El fuego se utilizó como arma prácticamente desde su invención. La táctica más sencilla consistía en provocar incendios que impidieran o ralentizasen el avance de enemigo, o que, en el peor de los casos, lo aniquilaran. Esta última táctica fue utilizada por los etolios (426 - 425 a. C.), para defenderse de los atenienses en Egicio (Th. III, 98), y por Demetrio contra los lacedemonios en el monte Lirceo. En esta campaña, Demetrio también incendió varios carros para ganar tiempo durante la retirada de sus hombres (Poliaen. IV, 7.9 - 10).

Una táctica más elaborada consistió envolver las flechas con fibras vegetales (cáñamo, lino o paja) y prenderles fuego. En relieves asirios del siglo IX a. C., ya 
aparecen representadas flechas incendiarias y tenemos constancia de que los persas recurrían a ellas con frecuencia. En Grecia el empleo de proyectiles incendiarios se documenta durante el transcurso de las Guerras Médicas, concretamente en el año 480 a. C., cuando los persas invadieron Atenas. Ante el avance persa, los atenienses abandonaron la ciudad. En ella sólo quedaron un pequeño grupo de sacerdotes y hombres que, para defenderse, construyeron una empalizada de madera en torno al templo de Atenea e hicieron rodar, colina abajo, grandes piedras. Los persas contraatacaban lanzándoles flechas envueltas con copos de estopa a las que prendían fuego (Hdt. 8. 51 - 53). También durante el sitio de Platea (429 a. C.), se recurrió a este tipo de proyectiles. El siguiente paso consistió en aplicar el fuego a las máquinas de guerra y más concretamente a las catapultas. Debido a la rapidez del lanzamiento los proyectiles se apagaban y no era posible disparar las catapultas con la máxima tensión, pero el hecho de poder lanzar mecánicamente fuego fue todo un logro. Para elevar la efectividad de los lanzamientos se diseñaron las denominadas bolas de fuego; se trataba de recipientes rellenos de azufre, pez, serrín de pino, estopa y resina o incienso molido que al impactar derramaban el líquido incendiario y provocaban fuegos más grandes. Durante el asedio de la isla de Rodas (304 a. C.), tras un ataque especialmente intenso, Demetrio Poliorcetes ordenó a sus hombres que recuperaran y contabilizaran los proyectiles que se habían disparado. La cifra resultó sorprendente: los rodios habían disparado más de 800 bolas de fuego y 1500 dardos (Diod. XX, 97. 2).

Los proyectiles incendiarios fuesen del tipo que fuesen resultaban muy eficaces en ataques por sorpresa o si se lanzaban contra construcciones de madera como casas, máquinas de guerra, empalizadas, etc., siempre y cuando estas no estuviesen debidamente protegidas. Generalmente los incendios provocados con ellos se sofocaban fácilmente si se actuaba con prontitud. Una estrategia más sofisticada y también más efectiva consistía en provocar varios focos simultáneos lo que obligaba a los soldados a dividirse para sofocarlos, descuidando con ello la defensa.

Los griegos no tardaron mucho en buscar algo que generara fuegos más voraces y por tanto más destructivos. En un primer momento recurrieron a la brea y, tiempo después, lograron destilar esta para obtener la trementina. Pronto descubrieron otros acelerantes minerales capaces de avivar o elevar el poder combustible de las armas.

Igualmente, pronto descubrieron que el fuego se podía utilizar de otros modos. Por ejemplo, durante el sitio de Platea, los espartanos se dieron de cuenta de que los proyectiles que lanzaban contra la ciudad no daban los resultados esperados e idearon una nueva táctica para reducirla. Esta consistió en apilar grandes cantidades de leña junto a la muralla, impregnarlas de pez y azufre y prenderle fuego (Th. II, 97). El empleo del azufre fue algo novedoso, ya que al arder generó dióxido de 
azufre, un gas irrespirable y muy nocivo si se inhala en grandes cantidades. Aunque desconocemos si los espartanos estaban al tanto las consecuencias de lanzar el azufre a las llamas o si improvisaron la táctica, este asedio constituye uno de los primeros casos documentados de una sustancia química incendiaria perfeccionada para generar un gas tóxico.

Otra táctica consistía en verter brea sobre los enemigos y las máquinas de asedio, seguidas de manojos de cáñamo y pequeñas cantidades de azufre que se fijarían a la brea y prenderles fuego haciendo descender haces de astillas encendidas. Especialmente efectivos resultaban los denominados erizos; se trataba de artefactos de madera, provistos de púas metálicas para facilitar el agarre contra el objetivo y rellenos de material incendiario. Más simple, aunque no por ello menos eficaz, resulta la táctica utilizada por los fenicios en Tiro (332 a. C.): llenaron cuencos de bronce con arena fina y pequeñas limaduras de metal; calentaron la arena hasta que estuvo al rojo vivo y catapultaron los recipientes sobre los soldados de Alejandro Magno. La arena y las virutas de metal se filtraron dentro de la armadura de los soldados, provocándoles quemaduras (Diod. XVII, 44.1 - 3).

En el apartado de artilugios incendiarios se incluirían el célebre lanzallamas utilizado por los beocios para tomar la ciudad de Delio y la máquina que se utilizó en el asedio de Lecito (424 a. C.). El primero estaba formado por una viga de madera dividida en dos partes ensambladas, cuyo interior se había vaciado y recubierto con hierro; en el extremo delantero llevaba un caldero con carbones encendidos, azufre y pez. Varios fuelles insuflaban aire, originándose violentas llamaradas. Durante el asedio de Lecito, las fuentes aluden a una máquina, sin concretar sus características, para intentar prenderle fuego a la empalizada (Th. IV, 100 y 115).

El fuego también se podía utilizar para sabotear las labores de minado que realizaba el enemigo. Con esta táctica se pretendía quemar o asfixiar a los soldados o forzar el abandono del minado. El método era sencillo: se arrojaba madera y serrín al interior de los túneles y se les prendía fuego. El humo ahogaba a los soldados que debían abandonar la excavación.

Finalmente, en la guerra naval, el fuego también fue un recurso al que se recurrió con frecuencia. En este caso la estrategia consistía en llenar una o varias naves con madera, sarmientos y matojos a los que se añadían pez, azufre y otras sustancias inflamables y lanzarla ardiendo contra la escuadra enemiga. Los denominados brulotes se utilizaron durante los asedios de Siracusa (415 - 413 a. C.) y Rodas (305 a. C.), también emplearon en el asedio de Tiro (332 a. C.), donde ya se observa un perfeccionamiento de la táctica (Th. VII, 53; Diod. 86. 3; Arr. II, 19).

Como ocurría con las armas anteriormente comentadas, el empleo de artefactos incendiarios prolongaba cruelmente la agonía de las víctimas o le provocaban dolores insoportables y heridas incurables por lo que se consideraban algo aborrecible. 


\section{Conclusiones}

Las armas biológicas o bacteriológicas son aquellas que utilizan organismos vivos para matar o incapacitar al enemigo; entre ellas se incluyen las bacterias infecciosas que se multiplican (virus, parásitos y esporas), las toxinas vegetales y las sustancias venenosas derivadas de animales (insectos, reptiles, anfibios, peces o criaturas marinas, etc.). También se suman a este grupo los insectos y demás animales empleados con fines bélicos. Por el contrario, la guerra química es aquella que utiliza gases venenosos, materiales incendiarios (entre los que se incluirían los elementos abrasivos, cegadores y asfixiantes) y los venenos minerales.

Desde la antigüedad se constata el uso de armas químicas y biológicas y Grecia no fue una excepción a esta norma. Aunque las fuentes pretenden transmitir la idea de que los griegos respetaban las normas de la guerra, valorando el juego limpio, el honor, la valentía y la destreza de los soldados, lo cierto es que generalmente, no se establecieron de forma estricta reglas formales que rigieran los enfrentamientos. En esta disyuntiva se situaría el empleo de estrategias "poco éticas” y las armas manipuladas. En un principio los griegos, como muchas otras civilizaciones antiguas, se sirvieron de lo que la naturaleza les ofrecía (venenos vegetales o animales para emponzoñar las armas, enjambres de abejas y avispas para atosigar al enemigo, hacer acampar al enemigo en sitios insalubres que les provocasen enfermedades, etc.), para fabricar las primeras armas bioquímicas. Con el tiempo estas armas se perfeccionaron para conseguir un mayor número de víctimas y unos efectos más devastadores. Por ejemplo los escitas no emponzoñaban sus flechas simplemente con veneno; ellos utilizaron una mezcla de su invención denominada scythicon, que contenía veneno de víbora y suero humano entre otros componentes. Se iniciaba así una carrera armamentística que llega hasta la actualidad. Uno de los elementos que más posibilidades ofreció fue el fuego. En un principio se utilizaba para crear incendios que sorprendieran y perturbaran los planes del enemigo pero con el tiempo, aditivos como la brea o el azufre ofrecieron múltiples posibilidades pues no solo aceleraban la combustión sino que generaban gases y humos tóxicos que obligaban al enemigo a rendirse o abandonar momentáneamente el enfrentamiento. El fuego también se aplicó a las flechas, surgiendo así los proyectiles incendiarios que posteriormente evolucionaron hacia las bolas de fuego y artefactos como el célebre lanzallamas beocio.

A medida que las armas bioquímicas se fueron perfeccionando, la opinión sobre su empleo también cambió y lejos de considerarse como algo deshonroso y propio de cobardes, no sólo se justificó, sino que llegó a elogiarse su utilización, incluso si estas aniquilaban a toda una población como ocurrió en el 590 a. C., cuando fueron envenenados los suministros de agua de la ciudad de Cirra. Para- 
lelamente el empleo de armas bioquímicas supuso un cambio en las tácticas de guerra y añadió presión a los enfrentamientos ya que los soldados luchaban con la incertidumbre de no saber a lo que se exponían lo que les restaba concentración y elevaría el terror hasta límites insospechados.

Los principios de las armas químicas y biológicas que los griegos utilizaron en el campo de batalla ya fueron contemplados en el mito desde la perspectiva que ponen de manifiesto aspectos próximos a la realidad y al mundo coetáneo. La lección más importante quizás sea la de que una vez creadas, las armas y sus efectos resultan incontrolables, se vuelven resistentes y amenazan con la destrucción a generaciones enteras y a sus propios creadores: Heracles pensó que podría controlar sus flechas envenenadas, pero no fue así y Folo ejemplifica la facilidad con la que uno mismo podía auto infringirse accidentalmente una herida con estas armas. 


\section{Bibliografía}

\section{Fuentes CLÁsicas}

APOLODORO: Biblioteca mitológica. Epitomes (trad. y notas de J. GARCÍA MORENO).

Ed. Alianza, Madrid, 2004.

CURCIO RUFO, Q: Historia de Alejandro Magno (trad. y notas de F. PEJENAUTE RUBIO). Ed. Gredos, Madrid, 1986.

DIODORO SÍCULO (2004): Biblioteca histórica (trad. y notas de J. J. TORRES ESBARRANCH). Ed. Gredos, Madrid.

DIOSCÓRIDES ANAZARBEO, P: Acerca de la materia medicinal y de los venenos mortíferos. Edición digitalizada.

http://bibliotecadigitalhispanica.bne.es:80/webclient/DeliveryManager?application=DIG ITOOL-3\&owner=resourcediscovery\&custom_att_2=simple_viewer\&pid=22870.

ELIANO, C: Historia de los animales (trad. y notas de J. M. DÍAZ - REGAÑÓN LÓPEZ). Ed. Gredos, Madrid, 1984.

ENEAS EL TÁCTICO: Poliorcética. (trad. y notas de J. VELA TEJADA y F. MARTÍN GARCÍA). Ed. Gredos, Madrid, 1991.

ESTRABÓN: Geografía (trad. y notas de J. L. GARCÍA ALONSO). Ed. Gredos, Madrid, 2015.

FLAVIO ARRIANO, L: Anábasis de Alejandro (trad. y notas de A. GUZMÁN GUERRA). Ed. Gredos, Madrid, 1982.

HERÓDOTO: Historia (trad. y notas de M. BALASCH). Ed. Cátedra, Madrid, 2002.

HOMERO: Ilíada (trad. y notas de C. RODÍGUEZ ALONSO). Ed. Akal / clásica, Madrid, 1989.

HOMERO: Odisea (trad. y notas de J. L. CALVO). Ed. Cátedra, Madrid, 2006.

JENOFONTE: Ciropedia (trad. y notas de A. VEGAS SANSALVADOR). Ed. Gredos, Madrid, 1987.

JENOFONTE: Anábasis (trad. y notas de C. VARIAS). Ed. Cátedra, Madrid, 2006.

OVIDIO: Metamorfosis (trad. y notas de C. ÁLVAREZ y R. Ma . IGLESIAS). Ed. Catedra, Madrid, 1995.

PAUSANIAS: Descripción de Grecia (trad. y notas de HERRERO INGELMO, M. C.). Ed. Gredos, Madrid, 1994.

PLINIO: Historia Natural (trad. y notas de CANTÓ, J; GÓMEZ SANTAMARÍA, I; GONZÁLEZ MARÍN, S. y TARRIÑO, E). Ed. Cátedra, Madrid, 2002.

POLIENO: Estratagemas (trad. y notas de J. VELA TEJADA y F. MARTÍN GARCÍA). Ed. Gredos, Madrid, 1991.

QUINTO DE ESMIRNA: Posthoméricas (trad. y notas de F. GARCÍA ROMERO). Ed. Akal Clásica, Madrid, 1997. 
SÓFOCLES: Ayax (trad. y notas de ASSELA ALAMILLO). Ed. Gredos, Madrid, 1981.

SÓFOCLES: Filotectes (trad. y notas de ASSELA ALAMILLO). Ed. Gredos, Madrid, 1981. TUCÍDIDES: Historia de la Guerra del Peloponeso (trad. y notas de A. GUZMAN GUERRA). Ed. Alianza, Madrid, 1989.

VIRGILIO: Eneida (trad. y notas de J. DE ECHAVE - SUSTAETA). Ed. Gredos, Madrid, 1992.

\section{Historiografía MODERNA:}

AGHION I; BARBILLÓN C; LISARRAGUE, F. (1997): Guia iconográfica de los héroes y dioses de la antigüedad. Ed. Alianza, Madrid.

ÁLVAREZ RICO, M. G. (2010): El campamento militar griego. De Homero a Jenofonte. Tesis doctoral, Universidad Autónoma de Madrid, Madrid.

ANGLIM, S; JESTICE, P. G; RICE, R. S; RUSCH, S. M; SERRATI, J. (2007): Técnicas bélicas del mundo Antiguo (3000 a. C. -500 d. C.). Ed. Libsa, Madrid.

CAROD - ARTAL, F. J. (2013): "Plantas psicoactivas en la Antigua Grecia”, en Neurosciences and History 1 (1). Ed. Sociedad española de Neurología, pp. 28 - 38.

CARREÑO GUERRA, M. P: "Guerra y peste en Atenas. Revisión sobre el posible origen de la epidemia ateniense (430 - 426 a. C.), en Asclepio, no 71 (1), 2019, p. 249. DE SOUZA, F. (2008): La guerra en el Mundo Antiguo. Ed. Akal, Madrid.

GARLAN, Y. (2003): La guerra en la Antigüedad. Ed. Alderabán, Madrid.

KEEGAN, J. (1995): Historia de la Guerra. Ed. Planeta, Barcelona.

MAYOR, A. (2018): Fuego griego, flechas envenenadas y escorpiones: La guerra química y biológica en la antigüedad. Ed. Desperta Ferro, Madrid.

QUESADA SANZ, F. (2003): "Lavar con sangre la humillación. Armas y valores del guerrero en la Odisea" en Sobre la Odisea. Visiones desde el mito y la Arqueología. Ed. Polifemo, Madrid, pp. 127 - 145.

SÁEZ ABAD, R. (2007): "La técnica militar en el mundo Antiguo", en Monografías Emeritenses, $\mathrm{n}^{\circ}$ 10. Ed. Museo Nacional de arte romano, Mérida, pp. 37 - 66.

SEKUNDA, N. (2009): Alejandro Magno III. El Ejército de Alejandro. Ed. RBA, Madrid. SIEBLER, M. (2002): La guerra de Troya. Ed. Ariel, Barcelona.

V.V.A.A. (1979): Fragmentos de épica griega arcaica. Ed. Gredos, Madrid. 
